Journal of Southeast Asian

2008

\title{
Hmong Parents Critical Reflections on Their Childrens Heritage Language Maintenance
}

Terry Yang

Lao Community of Stockton, Inc, tyd2005@sbcglobal.net

Follow this and additional works at: https://docs.lib.purdue.edu/jsaaea

Part of the Asian American Studies Commons

\section{Recommended Citation}

Yang, Terry (2008) "Hmong Parents Critical Reflections on Their Childrens Heritage Language Maintenance," Journal of Southeast Asian American Education and Advancement. Vol. 3 : Iss. 1, Article 17.

DOI: $10.7771 / 2153-8999.1113$

Available at: https://docs.lib.purdue.edu/jsaaea/vol3/iss1/17

This document has been made available through Purdue e-Pubs, a service of the Purdue University Libraries. Please contact epubs@purdue.edu for additional information.

This is an Open Access journal. This means that it uses a funding model that does not charge readers or their institutions for access. Readers may freely read, download, copy, distribute, print, search, or link to the full texts of articles. This journal is covered under the CC BY-NC-ND license. 


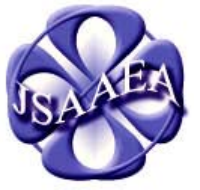

Volume 3
A peer-reviewed scholarly journal published by the National Association for the Education \& Advancement of Cambodian, Laotian, and Vietnamese Americans (NAFEA)

\title{
Hmong Parents' Critical Reflections on Their Children's Heritage Language Maintenance
}

\author{
Terry Yang \\ Lao Community of Stockton, Inc
}

\begin{abstract}
This study utilizes a qualitative method to explore the critical reflections of Hmong parents helping their children maintain their native language. Specifically, it examines parents' thoughts, feelings and experiences related to Hmong language maintenance. Findings reveal that Hmong parents worry about their children losing their ability to speak their native language. They believe that maintaining the Hmong language provides advantages in achieving academic success, attaining careers, and continuing to serve as role models in the community. Parents stressed the need to use Hmong at home in order to help their children develop and maintain the language. They reported some successes in doing so, while acknowledging several challenges.
\end{abstract}

\section{Introduction}

Today about 25 million Americans live in homes where a language other than English is spoken, particularly among the newly established immigrants from Latin America and the Asia Pacific (Cordova, 2000). Among the established Asian American communities, and beyond the second generation, the native language skills of many immigrant groups are slowly disappearing and being replaced by communication skills in the majority language of English.

As language minority children enter American schools, they encounter coercion to assimilate. It is difficult to achieve language maintenance under the strong influence of the outside force of language domination from the mainstream language and culture (Fishman, 1992). In her study of preschoolers, Fillmore (1991) found that the younger the children came in contact with assimilative forces, the greater the negative effect on their heritage language. Studies have also shown that in many Hmong families, children experienced language shift and cultural loss (Lee, 1999; 2002; Thao, 1995; Vang, 1998). Heritage language maintenance is a human resource for the children's individual psychological and educational development (Cummins, 2000). Studies have confirmed the benefits and advantages for minority children and their parents of learning the heritage language (Cummins, 2000).

Often the heritage language is maintained in a communicative role that serves a symbolic role in the central thought of ethnicity. This heritage language identifies group membership in

\section{@)}

SORERIGHISRESERVEDReaders are free to copy, display, and distribute this article, as long as the work is attributed to the author(s) and the Journal of Southeast Asian American Education \& Advancement, it is distributed for noncommercial purposes only, and no alteration or transformation is made in the work. More details of this Creative Commons license are available at http://creativecommons.org/licenses/by-nc-nd/3.0/. All other uses must be approved by the author(s) or JSAAEA. 
society. It is related to newly arrived immigrants' making better social, emotional, and educational adjustments (Krashen, 1992).

According to a study conducted by P. Lee (1999), Hmong teenagers born in the United States who are able to understand and speak Hmong and English orally had a lower level of proficiency in Hmong in comparison to their level of proficiency in English. Lee's study also concluded that although Hmong teenagers still saw the importance of maintaining the Hmong language, they were shifting from their home language to the English language. Even though they spoke Hmong and English interchangeably, they were more comfortable in the English language when conversing with siblings and their Hmong friends (Lee, 1999).

B. V. Lee (2002) found that in order for the Hmong parents to communicate with their children at home, they had to use English sparingly because they spoke it with heavy accents that could be very embarrassing to their children. However, a growing number of younger Hmong parents often find themselves speaking in English to their children. The parents and their children would more likely maintain the Hmong language if they both spoke it at home (Lee, 1999).

Heritage language is symbolically linked to its heritage culture. Krashen (1992) explains that speaking in the heritage language means providing a strong bond and enriching the connection between children, parents, and the heritage culture. Krashen also states that using the heritage language enables strong and closely-knit family communication among members of an ethnic group. By using the heritage language, parents can share their personal wisdom, family cultural values, beliefs, and understanding with their children (Fillmore, 1998). Family communication in the heritage language allows family members to share their thoughts and descriptions of the world. It helps them construct their shared evaluations of the world that form the core of the bonds that structure their daily lives (Cummins, 2000; Krashen, 1992; Lee, 1999, 2002). With a sense of strong family ties, communication in the heritage language can help the children interact with elders, foster parents, grandparents, and siblings. It can also help maintain a connection with their heritage tradition and culture.

Janssens (1987) studied Hmong adults at a community college regarding issues of assimilation and maintenance of language identity among the Hmong adults. He found that the Hmong adults desired to retain their cultural and language heritage while acculturating to the broader American society. He also found that Hmong parents emphasized the possibility of their children outwardly adopting the ways of other Americans by celebrating their holidays. The participants in Janssens' study favored this dual approach to assimilation and the maintenance of language identity. The parents believed that the language heritage of the Hmong should be kept and encouraged. According to P. Lee (1999) and Janssens (1987), Hmong children should be able to continue their traditions by participating in Hmong community activities, celebrations and perhaps by taking classes in Hmong language and culture.

In his study of Hmong language retention, Kirton (1990) found that most Hmong adults frequently speak the Hmong language and are likely to maintain their cultural identity. However, for the younger Hmong children, they frequently use more English when communicating with their peers. Kirton also found that Hmong children used Hmong and English interchangeably. Many Hmong parents have realized that their generation will be responsible for redefining the Hmong culture for their children. Many parents are concerned that their children do not sufficiently understand Hmong traditions because so much has changed and it has become difficult to know what is considered "traditional" and what has already been redefined. 
A study by Thao (1995) found that the elder Hmong people want to maintain their language and culture. The majority of parents also encouraged their children to speak English more often. Thao's study determined that the adults want to keep their cultural values and practices and they hope the younger generation will pass them on to their children. The Hmong parents in Thao's study further elaborated that being Hmong also means that one must know the traditional songs, dances, and poetry. Thus these parents felt that it is very important to keep the Hmong arts and crafts traditions and to pass them on to the younger generation of Hmong children.

Research on other minority groups has also helped inform this study. A study by Blakes (1998) engaged Lao refugee parents in dialogues regarding their children's maintenance of their home language. Blakes found that those parents who had a keen interest in preserving their culture felt miserable about their children. Participants lost control of their children regarding the use of the Lao language and maintenance of the culture and tradition. Blakes described how one couple in her study complained that as much as they paid attention to their children and as much as they spent time with them doing their homework, there was something missing because they knew that their children did not understand their heritage language and culture. Despite the fact that parents tried very hard to maintain their cultural values and language, they were faced with enormous challenges that were beyond their control. However, Lao refugee parents have realized that in order to preserve their heritage language and culture, they must enforce their mother language at home (Blakes, 1998; see also Lee, 1999; 2002; Vang, 1998).

Ilano-Tenorio (1996) has conducted research on language and identity with Filipino Americans, specifically children of immigrants. Ilano-Tenorio found that the participants whose parents immigrated to the United States had the advantage of being exposed to English early in school in the Philippines where it was the language of instruction. Only one participant was able to maintain fluency in Tagalog. Their language loss contributed to their loss of connection to their parents and family. They experienced self-doubt in their personal struggles to maintain or regain their home language. They felt that being able to speak Tagalong would have made their lives more whole and complete. The participants in Ilano-Tenorio's study felt that the Filipino American community needs to be more supportive of native speakers and non-native speakers learning Filipino. All of the participants concurred with the need to have more classes at the college and university level teaching Philippine languages as well as classes on Filipino history, culture, and issues.

In 1995, a study by O'Leary on the variation in language attitudes and behaviors of Vietnamese refugees in the Washington D.C. area found that Vietnamese proficiency was strongest among older adults, and weakest among teenagers. When asked if subjects thought that many Vietnamese children had difficulty understanding when their parents spoke Vietnamese, $83.2 \%$ of all respondents agreed with this statement, $9.3 \%$ were uncertain and $7.5 \%$ of respondents disagreed (O’Leary, 1995). In fact, all teenagers reported using English usually or always in the home, while other respondents in their twenties preferred using Vietnamese more often than English in the home domain. In addition, respondents over thirty chose Vietnamese more frequently than English. It was quite evident that there was a drastic language change between various generations.

Heritage language maintenance helps keep the connection between children, their culture, and their community (Banks \& Banks, 1993). It is important to recognize this connection because the majority of the Hmong children do not speak fluent Hmong. 


\section{Theoretical Framework}

History has shown that the United States developed from different nationalities and ethnic groups from around the world. Each ethnic group that lives in the United States contributes their language and cultural values into the mainstream of this nation (Conner, 1977). The theoretical framework of this study is based on the theories of heritage language maintenance and loss.

Due to political pressure for minority children to give up their home language and learn English as quickly as possible, children of immigrants born and raised in the United States are rapidly losing their heritage language. Fishman (1992) describes four stages of language change — from bilingualism to monolingualism—among immigrants and their descendents:

1. Initial stage: Immigrants acquire English by way of their mother tongue. Their utilization of English is only when they are in the work place, or when their mother tongue is insufficient for their needs.

2. Second stage: Immigrants acquire better English and can use English or their mother tongue to communicate to one another, but they still feel more comfortable with their mother tongue.

3. Third stage: Speakers are fluent in both languages; however English starts to become more dominant.

4. Fourth stage: English has displaced the mother tongue except for occasional situations when the mother tongue is the only choice.

These language patterns described by Fishman are based on his research on language maintenance and language shift among immigrants in the United States. Fishman's research also applies to the language maintenance and change among the Hmong children in the United States. To date, little research has been done on the effects of heritage language development.

\section{Purpose of the Study}

There is very little research on the concerns of Hmong parents' about their children's heritage language maintenance. In the present day, many Hmong children have difficulty with the spoken Hmong language. Hmong children frequently speak English at home and at school. When asked to translate the Hmong language into English, they often translate with uncertainty or are unable to do so (Lee, 1999). Most Hmong children who grow up in the United States do not speak Hmong as well as they speak English and often depend on an interpreter when they need to meet with their elderly Hmong parents (Lee, 1999; see also Vang, 1990). This study examines the experiences of parents and the challenges they face when helping their children maintain the Hmong language.

The purpose of this participatory study is to explore the critical reflections of Hmong parents in helping their children maintain the language. Specifically, it examines their thoughts and experiences related to Hmong language maintenance in the United States. The specific research questions addressed are: (1) What are Hmong adults' thoughts on the advantages of using the Hmong language for the younger generation in the United States? (2) What are the disadvantages of using the Hmong language by the younger generation? (3) How do parents try to maintain their heritage language in the United States? (4) How successful have parents been in 
helping their children maintain their heritage language in the United States? and (5) What are the challenges parents face in helping their children maintain their heritage language?

\section{Research Design}

Considering the exploratory nature of the study, the participatory dialogue methodology was considered the most appropriate. Ada and Beutel (1993) state that participatory research: (a) is a committed dialogue between the researcher and the community; (b) is based on the understanding of human characteristics; (c) serves as knowledge and power in oppressed populations; and (d) is a challenge for researchers committed to social justice.

Participatory research employs the process of dialogic retrospection. Freire (1982) explains that this research design consists of three parts. First, it is initiated through a problem or situation that forms the basis of the inquiry and is researched together by the researcher and the participants. Next, through this process of inquiry and dialogue, the researcher and participants learn about the world and about themselves, thus engaging in a transformative educational experience. Lastly, through reflection and deepened understanding, they are able to take action towards resolving the issue that initiated the inquiry.

Thus, participatory research allows the researcher and the participants to have a better understanding of the issue being studied. In this study, the dialogues between the researcher and participants focuses on some of the life stories, hopes, struggles, and desires of the participants.

Table 1

\begin{tabular}{cccccc}
\multicolumn{2}{l}{ Participant Background } & & & \\
Name & Age & Sex & Birthplace & $\begin{array}{c}\text { Year Arrived } \\
\text { In U.S. }\end{array}$ & $\begin{array}{c}\text { Years in } \\
\text { U.S. }\end{array}$ \\
\hline TuLee & 54 & M & Laos & 1985 & 19 \\
Lue & 59 & M & Laos & 1980 & 24 \\
PaYia & 52 & F & Laos & 1988 & 16 \\
TsaiLia & 55 & F & Laos & 1990 & 14 \\
\hline
\end{tabular}

\section{Participants}

Four Hmong adult participants were selected at a conference in Sacramento where the research was announced. These participants were selected because they met the following criteria: (a) range in age from 45 to 60; (b) born between 1945 and 1958 in Laos; (c) migrated to the United States between 1980 and 1990; and (d) currently reside in the Sacramento area. Every effort was made to ensure that any unique identifying information has been excluded to maintain the confidentiality of the individual participants. Pseudonyms were used for the four participants. Information on each participant is provided in Table 1, and a detailed description of each follows.

TuLee is a 54-year-old male clan advisor. He speaks Hmong, Lao, and some English. He was born in NamHia, a rural town in Laos. As a child, he did not attend school due to poverty. At the age of 15, he joined the U.S. secret army in Laos to fight the North Vietnamese. After the Royal Laos government fell to the Pathet Lao in 1975, he fled to Thailand as a refugee with his wife, daughter, and two sons. In 1985, he brought his family to the United States. He currently assists the Hmong community in supporting the maintenance of Hmong culture and traditions. 
Lue is a 59-year-old male caregiver. He was born in Longlien Village, Laos. He speaks Hmong, Lao, and some English. He was a farmer during the Vietnam War in Laos. He did not have an opportunity to join the U.S. secret army due to the isolation of his village. In 1975, when the communists took over South Vietnam, Cambodia, and Laos, he took his family and they escaped into a new economic zone where they were able to continue doing agricultural work. In 1978 he moved to Thailand with his family. In 1980 he brought his family to the United States. He currently assists his two sons as a caregiver at home.

PaYia is a 52-year-old female Hmong story cloth maker. She was born in Pakhang Village, Laos. During the Vietnam War in Laos, she assisted her mother and father with cultivating their rice and corn fields. She did not receive formal education in her village due to the isolation of the village and its poverty situation. After the Communists took over Laos, she and her parents decided to remain. Since they had two rice fields and one large corn field, her parents refused to give them up to the people who remained in the village. They remained there until 1983 before they made their journey to Thailand. While in the Thai refugee camps, PaYia got married and had two daughters. She learned how to read and write the Hmong language. She also learned Thai and some English. In 1988 she decided to take her family for another unknown journey to the United States. Currently, she is involved with selling Hmong story cloths and other small coinage items. She believes education is the key to open a broader opportunity in the United States.

TsaiLia is a 55-year-old female teacher assistant. She was born in Dongmuang, Laos. She speaks, reads, and writes the Hmong language. She is also fluent in Lao and English. In her teenage years in Laos, she was able to attend school in Long Cheng province where the U.S. secret army base was located. During the time of war, she worked as a nurse caring for the wounded soldiers. In 1968, she got married. Her husband served in a different base camp. Several months after their marriage, he was killed when his base came under attack. TsaiLia decided not to remarry because she had to take care of her deceased husband's family in order to escape from Laos to Thailand. In 1976 she took her family and made a long journey across the Mekong River to Thailand. During their journey, they encountered many obstacles and dangers, including starvation, being pursued by Vietnamese soldiers, and having to pay a high price in order to cross the Mekong River. After many months in their journey, they finally reached the other side of the Thai border and later reached the Thai refugee camps, Ban Vinai. In 1990, she decided to take her family and made another journey to the Unite States. She attended adult school and was able to complete her General Educational Development degree (GED). She is currently working as a bilingual assistant with the Sacramento Unified School District.

\section{Data Collection}

In the data collection process, the researcher conducted individual dialogues with the four Hmong adult participants. He met with each participant, explained the purpose of the study, and assured confidentiality. Participants were engaged in dialogues twice during the course of the study. The dialogues were conducted in the Hmong language. The dialogues were audiotaped, transcribed, and presented to the participants for feedback on their accuracy. 


\section{Data Analysis}

The researcher reviewed the dialogues in search for generative themes. Ada and Beutel (1993) summarized dialogic retrospection in the following five steps: (a) recruiting participants; (b) collecting the data by conducting and recording the dialogues; (c) transcribing and analyzing the recorded dialogues and discussing the text with the participants in search for generative themes; (d) reflecting on the dialogues with the participants; and (e) constructing meaning through an integrative analysis of the dialogues.

In this participatory research, the researcher announced and recruited the participants. He collected the data by recording the dialogues using audio tapes. Once the dialogues were completed, the researcher transcribed and analyzed the text and discussed them with the participants in search for generative themes. The researcher also shared the dialogues with the participants for reflections and meaning construction through an integrative analysis of the dialogues.

\section{Findings}

The participants' critical reflections focused on the following topics: (a) advantages of using the Hmong language for the younger generation; (b) disadvantages of using the Hmong language; (c) their efforts to maintain their heritage language in their homes with their children; (d) how successful have they been in maintaining their heritage language; and (e) challenges they faced in the maintaining their heritage language. The participants' reflections are presented here according to the research questions addressed in the study. Quotations in Hmong have been translated by the researcher into English and the translations were checked for accuracy by another Hmong educator.

\section{Advantages of Using the Hmong Language for the Younger Generation}

The Hmong parents cited several advantages for using their heritage language with their children and thought it should be maintained. Maintaining the Hmong language could result in more job opportunities and help them and their children in their schooling. However, they were concerned about their children not being able to speak Hmong.

TuLee said that using the Hmong language can help the youth learn the traditional way of life so that in case they go back home to Laos, the children would not feel alienated from the native culture. When children speak their own language and maintain their culture, they are likely to have more job opportunities and gain respect from their own community and the community at large. Lue said that he always encourages his children to speak Hmong because it is easier for him to understand them in their language. He further elaborated that children should know how to speak Hmong if they are to have a sense of belonging with the Hmong people. PaYia said that the Hmong language is very important to children, and they must try to maintain it as much as possible. She is very apprehensive about her children who were born in the United States. She told the researcher that just speaking the language was not enough; children should be able to read and write in Hmong:

Yog, kuv tus tub thiab tus ntxhais yeej nyiam hais lus hmoob thaum lub sij hawm peb sib tham. Ua rau kuj yooj yooj yim lawm ntau heev rau kuv thiab kuv cov me nyuam. 
Yes, my sons and daughters still speak Hmong when we talk with them. My sons and daughters always talk with me in Hmong. It makes a whole lot of difference and is easier for us.

For other parents, it is a lot harder for them to understand English. Since their children did not want to speak Hmong, it was difficult and sometime resulted in conflict. Lue said that his sons and daughters who were born in the United States did not want to speak Hmong with him. When I asked him how often they spoke Hmong to each other, he said:

Kuv cov tub thiab ntxhais hais lus Askiv rau kuv xwb. Kuv nyuaj siab kawg tham sis cov me nyuam hais tias kuv yuav tsum tau ua li lawv hais vim peb nyob rau America.

My sons and daughters often use English whenever we communicate with each other. I really have a hard time sometimes but my children said that I would have to learn to cooperate with them because this is America.

In the dialogue with TsaiLia, she said that she felt she had no control over her children because they only spoke English and it was difficult for her to understand them. PaYia described having a similar problem:

Thaum kuv nrog kuv tus me nyuam tham, lawv hais lus Askiv rau kuv xwb. Kuv cov me nyuam yeej hais lus Askiv nrog cov yau ntau dua. Kuv ntseeg tias peb cov lus hmoob ces yeej yuav ploj zuj zus mus. Muaj qee lub sij hawm kuj ua kuv nyuaj siab kawg tiam sis kuv yeej pab tsis tau li thiab. Kuv xav kom muaj kev pab los ntawm tej lub tsev kawm tawv.

When I speak with my children, they often answer back in English. Most of the time, they use English with their siblings and friends. I think that our language will be lost when our children do not want to use it. Sometime it makes me very sad but there is nothing I can do to help. I hope there is help outside in the community and the school.

Lue also agreed that his children should speak Hmong because they need to maintain the Hmong language. Lue further stated that when children know how to speak their own language, they have a sense of belonging to their culture and when children could not speak, read, and write Hmong, he believed they were not Hmong. According to Lue, "If one cannot speak his or her own native language, the individual has excluded himself or herself from the group." It is believed that when a person cannot speak his or her own language, this individual has also lost his or her own cultural identity.

TuLee suggested that when children know two or more languages, they are likely to gain access to education and jobs more than their counterparts. He agreed that the ability to speak, read, and write the Hmong language resulted in advantages for the younger generation. TsaiLia further elaborated her point of view, "Being able to speak, read, and write the Hmong language can help the younger children find a job more easily and have more opportunities when the employers look for bilingual Hmong interpreters." She further stated, "My son is just 13 years old and he speaks Hmong with me sometimes." Lue agreed that when the younger children speak, read, and write the Hmong language, they have more job opportunities. TuLee also had a 
similar opinion about knowing many languages. He said that today the Hmong people are growing in number and more Hmong interpreters will be needed for the Hmong people when they go to the hospital or social security office. Proficiency in Hmong will give the younger generation an advantage as the need for interpreters arise in the Hmong community.

The participants agreed that when children are able to communicate using their own language, they have advantages in achieving academic success that will lead to a promising career. The younger Hmong generation is able to continue their roles in the community and teach their siblings if necessary.

When these participants migrated to the United States, they hoped that their children would maintain their language and at the same time learn a new language. Lue said that the Hmong language could be used only in certain situations and that for a person to be successful in the United States, English must be learned first. TsaiLia also agreed that when she arrived in the United States, she hoped her children would learn English and then find a job. She did not consider how her children's maintenance of the Hmong language could also help them to be successful in America. As the Hmong population dramatically increases, the need for the Hmong language has become more important. In the Hmong community, it is culturally important to speak in the heritage language with the older Hmong persons, siblings, and friends.

Even though the four parents agreed on the need for their children to learn and maintain the Hmong language, TuLee said that he wanted his children to take advantage of the English language. Knowing the English language makes a person's life easier in the United States:

Kuv qhia kom kuv cov me nyuam hais lus hmoob thaum muaj neeg hmoob tauj. Lus hmoob tsuas yog zoo rau yam puav xwb. Kuv pom zoo cia kuv cov me nyuam hais lus Askiv feem ntau dua vim tias txoj kev nrhiav noj nrhiav haus nyob rau lub teb chaws America.

I often tell my children to speak Hmong only when a Hmong person is around. It is good only for certain situations. I encouraged my children to use English more because it is a means of survival in this country. When my children learn English very well, I am very happy. Besides the Hmong language, I will try to encourage them to learn other languages but is up to them. I will not force this because I think English is the most important language in this country. (TuLee)

Lue blamed himself for not educating his children to learn Hmong and said he felt shame because his children can not communicate in Hmong. He said, "It is a shame for us parents who cannot provide the necessary language for our children, especially Hmong because we are Hmong. We should teach our children our heritage language and pass it on to the future generation."

PaYia said that the Hmong people migrated to the United States with the hope to find better opportunities for their children. However, many lost their heritage language because they lived in isolated areas where there were no other Hmong families. Therefore, as time passed, their children were no longer able to speak Hmong. Lue also agreed that when parents move away from the Hmong community, their children may lose the language because the children would no longer have Hmong friends at school or in the community. 


\section{Disadvantages of Using the Hmong Language}

According to the parents, in some cases, there are disadvantages for using the Hmong language by the younger generation. They felt this is especially true in a job interview setting where the Hmong language is not necessary. TsaiLia said that she would like her children to speak English only because it is a means to finding a white collar job within mainstream society. According to TsaiLia,

We consider ourselves as Americans and our children should be able to speak English in most places such as school and in the work place. If our children speak Hmong, other people would know who they are and would make fun of them.

She further elaborated that when she was in a store shopping, she experienced humiliation when she used the Hmong language to communicate with her friend. Lue expressed his concerns:

Peb zoo siab tias peb cov me nyuam hais tau lus hmoob, tiam sis peb xav kom lawv paub lus Askiv heev dua. Paub hais lus hmoob xwb tsis zoo vim tias yua tau paub lus Askiv es thiaj nrhiav tau hauj lwm.

We are proud of ourselves that our children speak Hmong but we would like them to catch up with the English language. It is no good for our children to speak Hmong in this country because they will need to go out and find a job.

PaYia added that:

Yog tias peb cov me nyuam mus nrhiav hauj lwm mas lawv yuav tsum paub lus tswv yeej tsis siv lus hmoob ua lus nug. Vim li no lus hmoob thiab tsis muaj nuj nqis heev.

If our children go out and look for a job, they must acquire the English language in order to get hired. What is the use of using the Hmong language if the employer does not interview in this language? Therefore, using the Hmong language is a disadvantage in some ways.

\section{Efforts to Maintain the Heritage Language}

The Hmong parents reported they are worried about the younger generation's loss of their mother tongue. They reported that their children often did not use the Hmong language in school or at home. When they talk to their children in Hmong, the children often respond in English. They encourage and remind their children to use the Hmong language when communicating. Three of the parents stated that they used Hmong not only at home, but also in all family gatherings, with relatives, and even in public places. This was the only way to maintain their language on a daily basis. TsaiLia described the importance of maintaining the Hmong language:

Lus hmoob yog peb li teej tug, yog tias peb ua poob lawm, peb yuav tsis yog hmoob. Yog tias peb tsis paub lus hmoob, peb yuav tsis yog hmoob. Peb yuav txaj muag rau lwm haiv neeg uas paub hais peb yam lus hmoob. Muaj qee tus yeej tsis yog hmoob tiam sis lawv 
hais lus hmoob zoo thiab paub kawg. Yog li no peb thiaj yuav tsum khaws peb cov lus kom zoo.

The Hmong language is a part of our identity, and if we were to lose it, we would no longer be Hmong. Without our mother tongue, we could not relate to our people. Furthermore, we would be ashamed of not knowing our own language because there are people out there who are not even Hmong and can speak our language better than we can. The fact that even other people can learn how to speak, read, and write Hmong makes it important for us, native speakers, to maintain and master our mother tongue, and to pass it on to future generations.

In the dialogues with the participants, they all agreed that they would like their children to maintain the Hmong language. TsaiLia stated that, "It is very important to speak Hmong with our children when we are with them. Even in a public place, children need to speak Hmong so that they will remember.” TuLee, TsaiLia, and Lue further supported the statement. They said that they have always used Hmong with their children and their children responded in Hmong, and sometimes in Hmong mixed with English. They really want their children to speak fluent Hmong because they want them to keep the Hmong language and culture. They made comments that their children grew up following the mainstream American culture and lost their heritage language. They have no control over their children's actions nor their linguistic preferences. They fear that the Hmong language will not be used by the younger generation.

Lue responded that he often used Hmong either at home or in school when he went to pick up his children. He wants his children to remember the language and culture so that they could pass these on to the next generation. TsaiLia also stressed the importance of maintaining Hmong. She always used Hmong when communicating with her children at home. However, when they go out in public places such as a party, a banquet, festival, or celebration, they speak with their children mostly in English. It is always hard for the children to maintain the Hmong language because they have to learn English, too. The parents expressed sadness because they cannot help their children maintain the Hmong language, so they let their children do what is best for them. However, the participants in this study would like for the children to speak both English and Hmong so that they remember who they are when they grow up.

\section{Success in Maintaining their Heritage Language}

Parents reported some success in maintaining the Hmong language at home by speaking it with their children. PaYia said that she used Hmong everyday at home with her children. She hopes that she can educate her children to learn Hmong, but she wants the school to provide materials in Hmong as well. She claims that her children know how to speak Hmong. She agrees that if her children do not use Hmong at home, they are less likely to maintain the language. It is very important for the adults to always to speak Hmong whenever they can and wherever they are:

Peb qhia tau peb cov me nyuam paub lus hmoob vim tias peb hais lus hmoob nrog lawv txhua hnub tsis hais hauv tsev los tom tej qhua. Peb tsis tos tsev kawm ntawv pab dabtsi. Peb yeej txhawb tau cov me nyuam hauv tsev. Thaum lawv nyob tom tsev kawm ntawv, peb xav kom lawv rau rau siab kawm Askiv xwb. Li no peb thiaj khaws tau peb cov lus hmoob. 
We are successful in helping our children maintain the Hmong language because we speak with them everyday in and out of the home. We expect them to answer back in Hmong every time we speak with them. We do not rely on the school to teach Hmong to our children. We can do it in the home. When they are in school, we want them to practice English as much as they can. That's how our children can maintain the native language. (TuLee)

TsaiLia agreed that she would like to help her children maintain the Hmong language. When she spoke to them in Hmong, she expected her children to respond in Hmong, but it was hard for her as she often had to repeat what she had said. According to her, "I always remind them to speak Hmong with me, and when they do not, I would remind them of the importance of the Hmong language.” The researcher believes that when English becomes dominant as the home language, many are faced with the problem of maintaining their native language.

The participants stressed that they wanted to keep and speak the Hmong language, but without resources and support, they were worried that they may not be able to maintain it for long. The participants saw the importance of maintaining the Hmong language, and they knew that their children would need to use it when talking with a Hmong person. PaYia's major concern with her children was the family relationship. She said that "I am very afraid one day my children may not connect themselves with the rest of the family due to lack of a common language.” When asked about what approach she had taken to address that particular problem, she answered "taking my children to all family gatherings."

\section{Challenges in Maintaining the Heritage Language}

Parents often encountered problems when assisting their children to maintain the Hmong language. Lue responded with the following statement when asked about the challenges Hmong parents face when assisting their children:

Thaum peb hais kom peb cov me nyuam hais lus hmoob, lawv hais tias lawv tsis nyiam hais lus hmoob vim tias lawv cov phooj ywg nyob tom tsev kawm ntawv hais lus Askiv $x w b$. Cov me nyuam teb tias lawv yuav xav hais lus dab tsi los yeej tsis muaj leej twg txwv tau. Muaj ntau zaus, cov me nyuam hais tias kom peb cov laus tsis txhob hais hais lawv, vim peb laus laus lawm. Lawv kom peb tsis txhob txiav lawv kev ywj siab thiab kev hais lus.

When we ask our children to speak in Hmong, our children reply that they really don't need any Hmong in this country because their friends in school mostly speak English. Besides, their children should be able to speak whatever language they prefer. Sometimes our children would not listen to us and because they think we are old people and we should never interfere with their learning and freedom.

TsaiLia pointed out that educational materials are not readily available in the Hmong language. The parents' concern is that their children spend more time in school and do homework in English only, and unfortunately not much time is left for anything else. There is no Hmong language school in the Sacramento area, this makes Hmong language maintenance that 
much more challenging. TuLee said that it is very important for their children to maintain the home language, but without resources it is a difficult task for them.

\section{Discussion}

Findings from this study reveal that Hmong parents worry about their children losing their ability to speak their native language. The parents in this study stressed the importance in maintaining the Hmong language and passing it on to the next generation.

They believe that maintaining the Hmong language could open more opportunities and assist their children with their schooling. The participants agreed that when children are able to communicate using their own language, they have advantages in achieving academic success that will lead to promising careers. In addition, the younger generation will be able to continue their roles in the Hmong community and teach their siblings if necessary.

Parents were optimistic about their children learning the Hmong language; however, at the same time, they also want their children to learn English. They believe children should be able to speak both languages to be successful in the United States. Some parents agreed that English would become the primary language for their children because they have to use it in the work place. The parents even expressed some concern that speaking the Hmong language may give their children some disadvantages as they might have fewer chances to compete for jobs with mainstream English speakers. Parents reported that they were sometimes harassed by other people for speaking Hmong. Nonetheless, when these participants migrated to the United States, they hoped that their children would maintain their language and at the same time learn a new language so that they would be able to live with the mainstream people in this country.

The parents stressed that the Hmong language is a part of their identity, and if they were to lose it, they would no longer be Hmong. Without the mother tongue, they could not relate to their own people. They would be ashamed of not knowing their own language. To maintain their language, they often use it to communicate with their children. Even in public places, the parents feel their children need to speak Hmong so that they can remember and appreciate who they are.

Parents reported some success in maintaining the Hmong language in their home by speaking with their children everyday. They expected their children to answer back in Hmong every time they spoke with them. They did not depend on the school to teach Hmong to their children. They agreed that they can teach it at home after the children return from school. When their children are in school, they want them to practice English as much as possible.

Despite the positive views from the parents, they also faced enormous challenges. They reported that sometimes their children were resistant and did not want to speak the Hmong language with them. Even though parents asked them to respond in Hmong, their children often replied in English. Many of the parents lacked proficiency in English. These parents felt they were too old and that it was impossible for them to attend school and learn English. Despite these challenges, these parents continue their efforts to help their children maintain their Hmong language.

\section{Conclusion}

The intent of this study was to understand Hmong parents' critical reflections on their children's heritage language maintenance. Findings from this study reveal the relationship between language, culture, and traditions. These findings support previous research with heritage 
language maintenance. Previous research underscores that if Hmong communities in the United States lose their heritage language, they also lose their culture, traditions, and ethnic identity because they are very much interrelated (Lee, 1999; Lee, 2002; Vang, 1998; Yang, 2005). Furthermore, research has found that there are common concerns about heritage language maintenance among other minority groups (Blakes, 1998; Ilano-Tenorio, 1996; O’Leary, 1995). This study along with these previous studies, have found that those parents who have a keen interest have tried very hard to preserve their heritage language and culture with their children.

Despite the fact that parents try very hard to keep their cultural values and language which they consider to be important, they face enormous challenges that they feel are beyond their control. As in previous research in similar situations, they experience self-doubt in their personal struggles to maintain or regain their home language (Ilano-Tenorio, 1996; Lee, 2002; Yang, 2005). However, the participants have realized that in order to preserve their language, culture, tradition, and Hmong identity, they must maintain the use of their native language at home.

Regarding the support of the educators and school administrators, the participants feel that neither of them encourages maintenance of the home language. In fact, the Sacramento children's schools do not offer Hmong classes for children to learn their heritage language. The participants believe that if there were a larger number of Hmong students, the school might have created opportunities for their children to learn their heritage language.

This study suggests that there is a need for the younger Hmong generation to learn the Hmong language for the purpose of academic success and connecting with the elder generation who cannot converse with them in English. Philosophical issues of this nature must be addressed in mainstream society; it must be made widely known that children's maintenance of their Hmong language can be useful in facilitating family communication, improving job opportunities, and assuring a bright future. Furthermore, it will enable these students to help provide services to and communicate with the older Hmong generation.

\section{Implications and Recommendations}

The findings of this study are specific only to the small group of Hmong parent participants from the Sacramento area and thus cannot be readily generalized to all Hmong populations in the United States. However, this research is consistent with other findings, as described above. The views and experiences of the four Hmong parents in this study are likely consistent with other Hmong parents in similar situations. Nonetheless, more research on Hmong language maintenance needs to be conducted with Hmong populations in other geographical areas to confirm this.

Another area of needed research is an exploration of administrators' and educators' views on offering Hmong heritage language programs. Finally, school libraries should be stocked with more books and resources on the Hmong language and culture. They should also provide special programs and presentations of performing arts by Hmong choral groups and dance groups in the schools. Hopefully, these recommendations will provide a more meaningful approach to help Hmong parents and their children maintain the Hmong language and culture in the United States. 


\section{References}

Ada, A. F., \& Beutel, C. (1993). Participatory research as a dialogue for social action. Unpublished manuscript paper. University of San Francisco, CA.

Banks, J. A., \& Banks, C. A. (1993). Multicultural education: Issues and perspectives. Needham Heights, MA: Allyn and Bacon.

Blakes, J. (1998). A participatory study of the attitudes of Lao parents and their children toward the use of Lao at home. Unpublished doctoral dissertation, University of Green Bay, Wisconsin.

Conner, J. W. (1977). An acculturation of an ethnic identity in Japanese-Americans. San Francisco: R \& E Research Associates, Inc.

Cordova, J. M. T. (2000). The language situation of Filipina/os: Diversity and complexity. Cambridge, England. Cambridge University Press.

Cummins, J. (2000). Bilingual, power, and pedagogy: Bilingual children in the crossfire. Clevedon, England: Multilingual Matters, Ltd.

Fillmore, L. (1998). When learning a second language means losing the first. Early Childhood Research Quarterly, 13, 458-480.

Fishman, J. A. (1992). Reversing language shift. Clevedon, England: Multilingual Matters, Ltd.

Freire, P. (1982). Creating alternative research method: Learning to do it by doing it. New Delhi, India: Society for Participatory Research in Asia.

Ilano, B. T. L. (1996). Filipino Americans, children of immigrants: A participatory research of language and identity. Unpublished doctoral dissertation, University of San Francisco, California.

Janssens, L. G. (1987). The integration of Hmong adults into American society through the community college. Unpublished doctoral dissertation, University of San Francisco, California.

Kirton, M. (1990). Language loss and language maintenance among the Hmong students: A participatory research. Unpublished doctoral dissertation, University of Minnesota, Minnesota.

Krashen, S. (1992). Fundamentals of language education. Torrance, CA: Laredo.

Lee, B. V. (2002). Hmong high school students' critical reflections on heritage language, academic success, and family communication. Unpublished doctoral dissertation, University of San Francisco, California. 
Lee, P. (1999). Language maintenance and language shift among second generation Hmong teenagers. Unpublished doctoral dissertation, University of San Francisco, California.

O’Leary, J. (1995). Preserving the Vietnamese language: A participatory research. Unpublished doctoral dissertation, University of Florida, Florida.

Thao, P. (1995). The Hmong home language and their children. Unpublished doctoral dissertation, University of Minnesota, Minnesota.

Vang, K. (1998). The relationship between cultural retention among selected Hmong parent, and the academic achievement of their children. Unpublished doctoral dissertation, University of San Francisco, California.

Vang, L. (1990). Grandmother's path, grandfather's way. Rancho Cordova, CA: Zeller Publishing Co.

Yang, T. (2005). Hmong parents' critical reflections on their children's heritage language maintenance. Unpublished doctoral dissertation, University of San Francisco, California.

\begin{abstract}
About the Author
Dr. Yang attended a Community College and graduated with a Law Enforcement Certificate and Administration of Justice degree. He further pursued his education at California State University, Sacramento and received a bachelor degree and a masters degree in Criminal Justice. He recently graduated with a doctorate in International and Multicultural Education from the University of San Francisco. During the course of his studies, Terry, a native speaker of Hmong, has also worked as a community service officer, campus patrol officer, and probation officer with the City and County of Sacramento. Currently, he is a leadership consultant for non-profit agencies in Stockton, Sacramento, Merced and Fresno. He assists with writing grant proposals and conducts research to strengthen organizations. He also works as a Program Supervisor with the California First 5 Project for the Parent as Teacher (PAT) Program, working with parents and also with children from birth to the age of five.
\end{abstract}




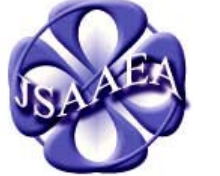

Volume 3

\section{Journal of Southeast Asian American Education \& Advancement} WWw.JSAAEA.org
A peer-reviewed scholarly journal published by the National Association for the Education \& Advancement of Cambodian, Laotian, and Vietnamese Americans (NAFEA)

\author{
Editor \\ Dr. Wayne E. Wright \\ University of Texas, San Antonio \\ Associate Editors \\ Dr. Chhany Sak-Humphry \\ University of Hawaii \\ Dr. KimOanh Nguyen-Lam \\ California State University, Long Beach \\ Book Review Editor \\ Dr. Leslie Turpin \\ School for International Training \\ Creative Works Editor \\ Phouang Hamilton \\ Washington Office of Superintendent of Public Instruction \\ Special Advisor \\ Anne Frank \\ University of California, Irvine, Southeast Asian Archives \\ Editorial Assistants \\ Shereen Bhalla \& Mariana Kuhl \\ University of Texas, San Antonio
}

Comments and questions for the editorial staff may be directed to jsaaea@lists.sis.utsa.edu

\title{
Editorial Review Board
}

\author{
Dr. Carl L. Bankston III \\ Tulane University \\ Dr. Phala Chea \\ Lowell Public Schools \\ Dr. Changming Duan \\ University of Missouri, Kansas City \\ Dr. Nancy H. Hornberger \\ University of Pennsylvania \\ Dr. Peter Nien-Chu Kiang \\ University of Massachusetts, Boston \\ Dr. Stacey Lee \\ University of Wisconsin, Madison
}

\author{
Dr. Pollie Bith-Melander \\ University of Hawaii at Manoa \\ Dr. George Chigas \\ University of Massachusetts, Lowell \\ Dr. Sophal Ear \\ Syracuse University \\ Dr. Samlong Inthaly \\ Minneapolis Public Schools \\ Dr. Kevin K. Kumashiro \\ University of Illinois, Chicago \\ Dr. David Chanpannha Ley \\ Montgomery County Public Schools
}


Dr. Sue Needham

California State University, Dominguez Hills

Dr. Max Niedzwiecki

Rights Working Group

Dr. Clara Park

California State University, Northridge

Dr. Loan T. Phan

University of New Hampshire

Dr. Karen Quintiliani

California State University, Long Beach

Dr. Fay Shin

California State University, Long Beach

Dr. Yer J. Thao

Portland State University

Dr. Khatharya Um

University of California, Berkeley

Dr. Terrence G. Wiley

Arizona State University
Dr. Bic Ngo

University of Wisconsin-Madison

Dr. Leakhena Nou

California State University, Long Beach

Dr. Mark Pfeifer

Texas A\&M University, Corpus Christi

Dr. Bounlieng Phommasouvanh Minnesota Department of Education

Dr. Kalyani Rai

University of Wisconsin, Milwaukee

Dr. Nancy J. Smith-Hefner Boston University

Dr. Myluong Tran

San Diego State University

Dr. Linda Trinh Vo

University of California, Irvine

Dr. Zha Blong Xiong

University of Minnesota

Dr. Kou Yang

California State University, Stanislaus

\section{Doctoral Student Editorial Review Board}

Keo Chea

University of Pennsylvania

Loan Dao

University of California, Berkeley

Ha Lam

Arizona State University

Vanna Som

Harvard University

Giang Pham

University of Minnesota

Tinou Tran

University of Houston, Texas

Phitsamay Sychitkokhong Uy

Harvard University
Vichet Chhuon

University of California, Santa Barbara

Annie BichLoan Duong

San Joaquin County Office of Education

Ravy Lao

University of California, Santa Barbara

Rassamichanh Souryasack

University of California, Santa Barbara

Layheng Ting

State University of New York, Albany

Loan Tran

University of California, Santa Barbara

Yang Sao Xiong

University of California, Los Angeles 